\title{
DIFERENTES COMMBNAÇÕES DE NPK NA PRODUÇÃO DO FEIJÃO-VAGEM EM SOLO ORGÂNICO ÁLICO DO VALE DO RIBEIRA (SP) (')
}

\author{
ISSAO ISHIMURA $\left({ }^{2,6}\right)$, CELI TEIXEIRA FEITOSA $\left({ }^{3.6}\right)$, \\ ROGERIO SALLES LISBĀO $\left({ }^{4,6}\right)$, FRANCISCO ANTONIO PASSOS( $\left({ }^{5,6}\right)$, \\ JOAO BAPTISTA FORNASIER $\left({ }^{4,6}\right)$ e MASSAHARU NODA $\left({ }^{27}\right.$ )
}

\begin{abstract}
RESUMO
Objetivando-se verificar o efeito de doses de fertilizantes $(0-0-0,118-192$ $186,236-384-372$ e 354-576-558 kg/ha de $\mathrm{N}-\mathrm{P}_{2} \mathrm{O}_{5}-\mathrm{K}_{2} \mathrm{O}$ respectivamente) na produção do feijao-vagem, cv. Teresópolis, desenvolveu-se um experimento na Estação Experimental de Pariquera-Açu em solo orgânico álico de alta acidez. Nas condiçoes do experimento, verificou-se apenas resposta linear e positiva altamente significativa para os seguintes caracteres estudados: produtividade total de vagens, produtividade de vagens comerciáveis e número total de vagens. Desse modo, as maiores produtividades em peso e número de vagens, em magnitude, foram obtidas quando se utilizou a dose máxima de NPK.
\end{abstract}

Termos de indexação: feijão-vagem, Phaseolus vulgaris L.; adubação.

(') Trabalho apresentado no XXIII Congresso Brasileiro de Olericultura, realizado no Rio de Janeiro (RJ) de 18 a 23 de julho de 1983. Recebido para publicação em 17 de janeiro de 1984.

$\left({ }^{2}\right)$ Estação Experimental de Pariquera-Açu, Instituto Agtonomico (IAC), Caixa Postal 28, 13100 - Campinas (SP).

$\left({ }^{3}\right)$ Seção de Fertilidade do Solo, IAC.

$\left({ }^{4}\right)$ Seção de Hortaliças Diversas, IAC.

(5) Seção de Hortaliças de Frutos, IAC.

${ }^{6}$ ) Com bolsa de suplementação do CNPq.

(7) Fitotecnista da Cooperação Técnica Brasil-Japão. 


\section{INTRODUÇÃO}

O feijão-vagem (Phaseolus vulgaris L) encontra-se entre as hortaliças mais importantes comercializadas pelas centrais de abastecimento do Estado de São Paulo e do Pars.

No Vale do Ribeira, esta leguminosa é cultivada principalmente no período março-setembro, possibilitando, assim, a obtenção de colheitas antecipadas às do Planalto paulista, com cotações compensadoras. Segundo BERNARDI (1967/68), o feijão-vagem se desenvolve nos mais diversos tipos de solo, com preferência aos arenosos, bem drenados, ricos em elementos minerais, matéria orgânica e pH na faixa de 5,5 a 6,8.

A fertilização racional do solo para seu cultivo em nosso meio ainda é um problema a ser resolvido. BERNARDI (1967/68) recomenda seu plantio em solos anteriormente adubados para outras culturas, principalmente tomate ou batatinha, para aproveitar o efeito residual dos adubos. Este fato também é confirmado por FILGUEIRA (1972), que dispensa a adubação de plantio dessa hortaliça quando o cultivo é feito em seguida a uma cultura bem adubada, como a do tomate, tendo, neste caso, a vantagem adicional de aproveitar o tutoramento.

CAMPINAS (1977) recomenda, para solos com médio teor em fosforo $\left(3-30 \mu \mathrm{g} / \mathrm{ml}\right.$ de $\mathbf{P}$ de TFSA), 40 gramas de $\mathrm{P}_{2} \mathrm{O}_{5}$ por metro de sulco e para solos com médio teor em potássio $(71-240 \mu \mathrm{g} / \mathrm{ml}$ de K de TFSA), 12 gramas de $\mathrm{K}_{2} \mathrm{O}$ por metro de sulco. Quanto ao nitrogênio, essa fonte recomen$\mathrm{da}$, independente de seu teor no solo, a utilização de $3 \mathrm{~g}$ por metro de sulco na adubação básica, e $12 \mathrm{~g}$ por metro de sulco, em cobertura, aos 20 e 40 dias após a emergência das plântulas, metade da dose por vez.

Contudo, as informações disponíveis sobre a nutrição do feijão-vagem, além de escassas, são, em sua maioria, originárias de trabalhos realizados no exterior, utilizando principalmente cultivares pertencentes ao tipo de crescimento determinado. THOMPSON \& KELLY (1957) relatam que plantas de feijão-vagem de crescimento indeterminado requerem mais fertilizantes do que as de crescimento determinado, devido a sua maior produtividade e ciclo mais longo.

Estudos mais detalhados e que analisam os efeitos dos nutrientes $\mathbf{N}$, $\mathrm{P}$ e $\mathrm{K}$ foram realizados na Flórida e Califórnia com cultivares de crescimento determinado (HILLS et alii, 1953; SIMS et alii, 1977). Todavia, sabe-se que as necessidades de fertilizantes variam de acordo com a cultura anterior, nivel de fertilidade do solo, tipo de solo, clima, e que o feijão-vagem de crescimento determinado não é considerado muito exigente quanto à adubação (SIMS et alii, 1977). 
Devido ao potencial do Vale do Ribeira para a cultura do feijãovagem e à escassez de informações sobre sua adubação na região, resolveu-se elaborar este trabalho de pesquisa, cujo principal objetivo foi verificar o efeito da adubação NPK na produção de vagens e em seus componentes, tomando como base a adubação normalmente adotada na região.

\section{MATERIAL E METODOS}

Utilizou-se o cultivar Teresópolis, pertencente ao tipo manteiga (vagem com seção transversal achatada), cujas plantas apresentam crescimento indeterminado, do tipo "trepador", e vagens verde-claras de boa aceitação no mercado. As sementes empregadas, de coloração marrom, foram fornecidas pela firma Agroflora - Reflorestamento e Agropecuária.

$O$ ensaio foi conduzido na Estação Experimental de Pariquera-Açu, do Instituto Agronômico do Estado de São Paulo, em solo do tipo orgânico álico, de textura argilosa e acidez elevada, e anteriormente.cultivado com milho.

Com base em observações de anos anteriores, fez-se a calagem cerca de quatro meses antes da semeadura, incorporando-se 5 toneladas por hectare de calcário dolomítico com PRTN igual a 65\%. Também foram incorporadas, no sulco, 5 toneladas de esterco curtido de galinha por hectare, trinta dias antes da semeadura, prática comumente utilizada pelos agricultores da região. O calcário e o esterco de galinha foram constantes para todos os tratamentos.

A análise química do solo, com base em amostra composta coletada entre os sulcos de plantio cerca de três meses após a calagem, realizada pela Seção de Fertilidade do Solo do IAC, apresentou os seguintes resultados: pH 4,90, matéria orgânica (\%) 12,10, alumínio, cálcio e magnésio 0,5,3,9 e $2,7(\mathrm{e} . \mathrm{mg} / 100 \mathrm{ml}$ de TFSA) respectivamente, potássio e fósforo $168,0 \mathrm{e}$ $15,9(\mu \mathrm{g} / \mathrm{ml}$ de TFSA $)$ respectivamenté.

Como fonte de nutrientes para o teste de efeito de combinações NPK, utilizou-se no plantio o adubo de fórmula 4-16-8 e, em cobertura, o sulfato de amônio $(20 \% \mathrm{~N})$ e o cloreto de potássio $\left(60 \% \mathrm{~K}_{2} \mathrm{O}\right)$.

$\mathrm{O}$ delineamento experimental foi blocos ao acaso, com quatro tratamentos e seis repetições. As parcelas constaram de quatro linhas de cinco plantas, ocupando uma área de $10 \mathrm{~m}^{2}(4 \mathrm{~m} \mathrm{X} \mathrm{2,5m),} \mathrm{sendo} \mathrm{consideradas}$ úteis as dez plantas das linhas centrais $\left(5 \mathrm{~m}^{2}\right)$, onde foram computados os dados. $\mathrm{O}$ espaçamento adotado foi $1 \mathrm{~m} \times 0,5 \mathrm{~m}$, e os tratamentos constaram de três combinações de doses de NPK, múltiplas, a saber: 1: testemunha (ausência da adubação NPK); 2: $N_{1} P_{1} K_{i}: 118-192-186 \mathrm{~kg} / \mathrm{ha} ; 3: \mathrm{N}_{2} \mathrm{P}_{2} \mathrm{~K}_{2}$ : 
236-384-372kg/ha e 4: $\mathrm{N}_{3} \mathrm{P}_{3} \mathrm{~K}_{3}: 354-576-558 \mathrm{~kg} / \mathrm{ha}$ respectivamente de $\mathrm{N}-\mathrm{P}_{2} \mathrm{O}_{3}-\mathrm{K}_{2} \mathrm{O}$. $\mathrm{O}$ tratamento $\mathrm{N}_{2} \mathrm{P}_{2} \mathrm{~K}_{2}$ corresponde à adubação normalmente usada pelos agricultores da regiâo, os quais recebem orientação técnica da Cooperativa Agrícola de Cotia.

$\mathrm{Na}$ adubação de plantic efetudada sete dias antes da semeadura, incorporou-se na linha o adubo de fórmula 4-16-8 a $10 \mathrm{~cm}$ de profundidade nas seguintes quantidades por tratamento adubado: $\mathrm{N}_{1} \mathrm{P}_{1} \mathrm{~K}_{1}-1.200 \mathrm{~kg} / \mathrm{ha}$, $\mathrm{N}_{2} \mathrm{P}_{2} \mathrm{~K}_{2}-2.400 \mathrm{~kg} / \mathrm{ha}$ e $\mathrm{N}_{3} \mathrm{P}_{3} \mathrm{~K}_{3}-3.600 \mathrm{~kg} / \mathrm{ha}$. Estas quantidades correspondem aos seguintes niveis de $\mathrm{N}-\mathrm{P}_{2} \mathrm{O}_{5}-\mathrm{K}_{2} \mathrm{O}$ por tratamento: $\mathrm{N}_{1} \mathrm{P}_{1} \mathrm{~K}_{1}$ : 48-192-96kg/ha, $\mathrm{N}_{2} \mathrm{P}_{2} \mathrm{~K}_{2}$ : 96-384-192kg/ha, $\mathrm{N}_{3} \mathrm{P}_{3} \mathrm{~K}_{3}: 144-576-288 \mathrm{~kg} / \mathrm{ha}$.

Dessa maneira, todo o fósforo foi aplicado no plantio, enquanto o nitrogênio e o potássio foram também fornecidos em cobertura, utilizando-se dos adubos simples já mencionados anteriormente. Assim, as doses e as épocas de aplicação da adubação em cobertura foram as seguintes por tratamento: $\mathrm{N}_{1} \mathbf{P}_{1} \mathrm{~K}_{1}: 70 \mathrm{~kg} / \mathrm{ha}$ de $\mathrm{N}$ e $90 \mathrm{~kg} /$ ha de $\mathrm{K}_{2} \mathrm{O}$ aplicados aos 20 dias após a emergência das plântulas; $\mathrm{N}_{2} \mathrm{P}_{2} \mathrm{~K}_{2}: 140 \mathrm{~kg} / \mathrm{ha}$ de $\mathrm{N}$ e $180 \mathrm{~kg} /$ ha de $\mathrm{K}_{2} \mathrm{O}$ aplicados aos 20 e 40 dias após a emergência das plântulas, metade da dose em cada aplicação; e $\mathrm{N}_{3} \mathrm{P}_{3} \mathrm{~K}_{3}: 210 \mathrm{~kg} /$ ha de $\mathrm{N}$ e $270 \mathrm{~kg} / \mathrm{ha}$ de $\mathrm{K}_{2} \mathrm{O}$ aplicados aos 20,40 e 60 dias após a emergência das plântulas, um terço da dose em cada aplicação.

A semeadura foi realizada em 27/5/1982. Durante o desenvolvimento da cultura, foram feitas irrigações por aspersão, capinas, estaqueamento e pulverizações visando ao controle de pragas e doenças.

As colheitas foram realizadas manualmente na freqüência de até três vezes por semana, à medida que as vagens atingiam o ponto de consumo. $O$ período de colheita estendeu-se de 6 de agosto a 22 de setembro de 1982. As vagens de cada parcela após cada colheita foram pesadas e contadas, sendo os dados transformados respectivamente em quilograma/hectare e número/hectare, obtendo-se a produtividade total $\mathrm{e} o$ número total de vagens.

A produtividade de vagens comerciáveis foi obtida pesando-se as vagens colhidas de cada parcela, que se apresentavam retas com comprimento em torno de $22 \mathrm{~cm}$, e livres de qualquer danificação. Mediante a relação entre o peso e o número de vagens, determinou-se também o peso médio da vagem.

Os dados expressos em número total de vagens foram transformados em $\sqrt{\mathrm{x}}$, para serem submetidos à análise de variância, enquanto os dados de produtividade total de vagens, produtividade de vagens comerciáveis, e peso médio de vagens, foram analisados diretamente. No tocante à produtividade total e comerciável de vagens, também foram determinadas as respectivas variações percentuais em relação à testemunha.

Após a realização da análise da variância, procedeu-se ao isolamento de cada um dos três graus de liberdade para tratamentos, a fim de avaliar se- 


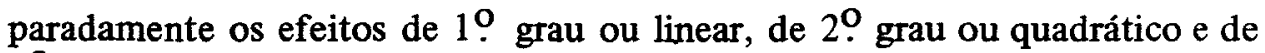
3. grau ou cúbico.

Visando computar o custo de adubação e o lucro proporcionado pelo produto colhido, foi elaborada uma análise econômica da adubação utilizada, comparando-se as rendas líquidas obtidas pela diferença entre a receita do produto e o gasto total de fertilizantes e corretivo. Para o cálculo da receita, levou-se em conta o preço da vagem, correspondente à média aritmética entre os preços máximos e mínimos ocorridos no período agosto-setembro de 1982 na CEAGESP, a saber, $\operatorname{Cr} \$ 110,00$ /quilograma.

Os preços dos fertilizantes e corretivo utilizados foram tomados em setembro de 1982, no comércio local.

\section{RESULTADOS E DISCUSSAXO}

No quadro 1 são apresentadas estimativas das médias referentes à produtividade total e comerciável: de vagens, assim como as respectivas variações percentuais e a percentagem de vagens comerciáveis.

QUADRO 1 - Produtividade total de vagens e sua variação percentual, produtividade de vagens comerciáveis e sua variação percentual, e porcentagem de vagens comerciáveis, obtidas em ensaio de adubação, na localidade de Pariquera-Açu (SP), em solo orgânico álico $\left({ }^{1}\right)$

\begin{tabular}{|c|c|c|c|c|c|}
\hline \multirow[t]{2}{*}{ Tratamentos } & \multicolumn{2}{|c|}{$\begin{array}{l}\text { Produtividade } \\
\text { total de vagens }\end{array}$} & \multicolumn{2}{|c|}{$\begin{array}{c}\text { Produtividade de } \\
\text { vagens comerciáveis }\end{array}$} & \multirow{2}{*}{$\begin{array}{c}\begin{array}{c}\text { Vagens } \\
\text { comerciáveis }\end{array} \\
\%\end{array}$} \\
\hline & $\mathrm{kg} / \mathrm{ha}$ & $\%$ & $\mathrm{~kg} / \mathrm{ha}$ & $\%$ & \\
\hline Testemunha & 18.967 & 100 & 12.167 & 100 & 64 \\
\hline$N_{1} P_{1} K_{1}$ & 20.467 & 107 & 13.100 & 107 & 64 \\
\hline $\mathbf{N}_{2} \mathbf{P}_{2} \mathbf{K}_{2}$ & 21.433 & 113 & 13.567 & 111 & 63 \\
\hline $\mathbf{N}_{3} \mathbf{P}_{3} \mathbf{K}_{3}$ & 23.000 & 121 & 14.567 & 119 & 63 \\
\hline F (Tratamentos) & $6,9 * *$ & - & $5,2 *$ & - & - \\
\hline F (Regressão linear) & $20,7^{* *}$ & - & $15,5^{* *}$ & - & - \\
\hline CV (\%) & 7,5 & - & 8,0 & - & - \\
\hline
\end{tabular}

(1) Média de seis repetições. 
No quadro 2 encontram-se as estimativas das médias do número total e peso médio de vagens.

QUADRO 2 - Número total e peso médio de vagens obtidos em ensaio de adubação realizado na localidade de Pariquera-Açu (SP), em solo orgânico álico $\left({ }^{1}\right)$

Tratamentos

Número total de vagens por hectare $\left({ }^{2}\right) \quad$ Peso médio de vagens

\begin{tabular}{lcc}
\hline & $\sqrt{\mathrm{x}}$ & $\mathrm{g}$ \\
Testemunha & 1.424 & 9,3 \\
$\mathrm{~N}_{\mathbf{1}} \mathbf{P}_{\mathbf{1}} \mathbf{K}_{\mathbf{1}}$ & 1.482 & 9,2 \\
$\mathrm{~N}_{2} \mathrm{P}_{\mathbf{2}} \mathrm{K}_{2}$ & 1.530 & 9,1 \\
$\mathrm{~N}_{3} \mathrm{P}_{\mathbf{3}} \mathrm{K}_{3}$ & 1.563 & 9,4 \\
\hline $\mathrm{F}$ (tratamentos) & $7,0^{* *}$ & $1,4 \mathrm{n} . \mathrm{s}$. \\
$\mathrm{F}$ (Regressão linear) & $20,7^{* *}$ & $0,014 \mathrm{n} . \mathrm{s}$. \\
$\mathrm{CV}(\%)$ & 3,7 & 2,4 \\
\hline
\end{tabular}

$\left({ }^{1}\right)$ Média de seis repetiçб̃es. $\left({ }^{2}\right)$ Dados transformados em $\sqrt{\mathrm{x}}$.

Pelo estudo da regressão na análise da variância, verificou-se apenas resposta linear e positiva altamente significativa, para os seguintes caracteres. estudados: produtividade total de vagens, produtividade de vagens comerciáveis e número total de vagens. Entretanto, quanto ao peso médio de vagens, não foi constatada signifícância para os componentes de $1 \%$, de 2 . e de 3. grau. Assim, as maiores produtividades em peso e número de vagens, em magnitude, foram obtidas quando se utilizou a dose máxima de NPK. Este fato, quanto à produtividade total e comerciável de vagens, também pode ser visualizado pela variação percentual.

Portanto, o tratamento $\mathrm{N}_{2} \mathrm{P}_{2} \mathrm{~K}_{2}$, que corresponde àquele normalmente empregado pelos agricultores da região, em solo orgânico álico, não foi adequado.

Com base nos resultados obtidos, verifica-se que a planta pode ter reagido ao nitrogênio aplicado conforme CÁSSERES (1966) e HILLS et alii (1953), em vista de a cultura ter sido conduzida em período chuvoso. Da mesma forma, o fósforo pode ter sido um nutriente importante para essa leguminosa, conforme relata FILGUEIRA (1972). Ainda pode ter havido resposta à adubação NPK, concordando com THOMPSON \& KELLY (1957), quando afirmam que o feijâo-vagem é uma leguminosa não eficiente. 
Por outro lado, como o presente trabalho foi realizado em solo orgânico álico de acidez elevada, onde normalmente se faz calagem pesada, espera-se que tenha havido resposta ao potássio. Talvez esse fato explique a divergência em relação à adubação potássica recomendada por CAMPINAS (1977).

No quadro 3, são apresentadas as informações para a análise econômica, a saber: produtividade total de vagens, receita bruta, custo total dos fertilizantes e corretivo, receita líquida e variação percentual da receita liquida.

QUADRO 3 - Produtividade total de vagens, receita bruta, custo total de fertilizantes e corretivo, receita líquida e variação percentual da receita líquida, para análise econômica de ensaio de adubação realizado na localidade de Pariquera-Açu (SP), em solo orgânico álico

\begin{tabular}{|c|c|c|c|c|c|}
\hline Tratamentos & $\begin{array}{l}\text { Produtividade } \\
\text { total de } \\
\text { vagens }\end{array}$ & $\begin{array}{l}\text { Receita } \\
\text { bruta } \\
\text { (A) }\end{array}$ & $\begin{array}{l}\text { Custo total de } \\
\text { fertilizantes } \\
\text { e corretivo (B) }\end{array}$ & $\begin{array}{l}\text { Receita } \\
\text { líquida } \\
\text { (A) - (B) }\end{array}$ & $\begin{array}{c}\text { Variação } \\
\text { percentual da } \\
\text { receita líquida }\end{array}$ \\
\hline & $\mathrm{kg} / \mathrm{ha}$ & & $-\mathrm{Cr} \$$ & 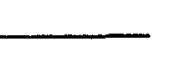 & $\%$ \\
\hline Testemunha & 18.967 & 2.086 .370 & 67.500 & 2.018 .870 & 100 \\
\hline$N_{1} P_{1} K_{1}$ & 20.467 & 2.251 .370 & 140.880 & 2.110 .490 & 105 \\
\hline $\mathrm{N}_{2} \mathrm{P}_{2} \mathrm{~K}_{2}$ & 21.433 & 2.357 .630 & 214.260 & 2.143 .370 & 106 \\
\hline $\mathbf{N}_{3} \mathbf{P}_{3} \mathrm{~K}_{3}$ & 23.000 & 2.530 .000 & 287.640 & 2.242 .360 & 111 \\
\hline
\end{tabular}

$\mathrm{O}$ estudo da análise econômica indicou que o ganho em produtividade proporcionado pela combinação $\mathrm{N}_{3} \mathrm{P}_{3} \mathrm{~K}_{3}$ compensou o gasto efetuado com tal adubação, como se pode notar pela receita líquida obtida. Em termos percentuais, esse ganho representou $5 \%$ a mais comparado com a combinação $\mathrm{N}_{2} \mathrm{P}_{2} \mathrm{~K}_{2}$, comprovando mais uma vez que, para o solo em questão, a adubação usada na região $\left(\mathrm{N}_{2} \mathrm{P}_{2} \mathrm{~K}_{2}\right)$ não é a mais adequada.

Os resultados deste trabalho, realizado em apenas um ano, fornecem informações preliminares aos agricultores do Vale do Ribeira, que cultivam o feijāo-vagem em solo orgânico álico.

Em vista dos resultados obtidos, as pesquisas na região terão continuidade, para que se possa ter conclusões seguras quanto à resposta qualiquantitativa dos macronutrientes estudados, inclusive em outros tipos de solo. 


\section{SUMMARY \\ INFLUENCE OF DIFFERENT LEVELS OF NPK FERTILIZERS ON THE YIELD OF POLE SNAP BEANS (PHASEOLUS VULGARIS L.)}

A trial was carried out at the Experimental Station of 'Pariquera-Açu', State of São Paulo, Brazil, on an organic soil, of high acidity $(\mathrm{pH}=4.9)$, to determine the influence of four levels of fertilizers $(0-0-0,118-192-186,236-384-372$ and $354-576-558 \mathrm{~kg} / \mathrm{ha}$ of $\mathrm{N}-\mathrm{P}_{2} \mathrm{O}_{5}-\mathrm{K}_{2} \mathrm{O}$ respectively) on the yield of pole snap beans, cultivar Teresópolis. The results showed that the pod yield increased with the increasing levels of fertilizers applied (inear effect). The highest yield of snap bean pods was obtained at the levels of $354-576-588 \mathrm{~kg} / \mathrm{ha}$ of $\mathrm{N}-\mathrm{P}_{2} \mathrm{O}_{5}-\mathrm{K}_{2} \mathrm{O}$, respectively. The results also showed that the average weight of pods remained constant and the number of pods increased linearly with the fertilizer levels.

Index terms: pole snap beans; Phaseolus vulgaris L.; fertilization.

\section{REFERENCIAS BIBLIOGRAFICAS}

BERNARDI, J.B. Cada vez mais feijão-vagem. In: COOPERATIVA AGRICOLA DE COTIA. Guia Rural. São Paulo, Fundação Coopercotia, 1967/68. p.148-150.

CAMPINAS. Instituto Agronômico. Tabelas de adubação e calagem. Campinas, 1977. 196p. (Boletim, 209)

CÁSSERES, E. Producción de hortalizas. Lima, Peru, Instituto Interamericano de Ciências Agrícolas de la OEA, 1966. 280p.

FILGUEIRA, F.A.R. Manual de olericultura: cultura e comercialização de hortaliças. São Paulo, Ceres, 1972. 451p.

HILLS, W.A., DARBY, J.F., THAMES JR., W.H. \& FORSEE JR., W.T. Bush snap bean production on the sandy soils of Florida. Gainesville, University of Florida, Agricultural Experiment Station, 1953. 23p. (Bulletin, 530)

SIMS, W.L., HARRINGTON, J.F. \& TYLER, K.B. Growing bush snap beans for mechanical harvest. Berkeley, University of California, Division of Agricultural Sciences, 1977. 8p. (Leaflet, 2674)

THOMPSON, H.C. \& KELLY, W.C. Vegetable crops. 5.ed. New York, McGraw Hill Book Company Inc., 1957. 61 1p. 